\title{
Reflect and rehydrate: improving junior doctor wellbeing and promotion of coping skills through peer-led education and support
}

\author{
Authors: Alexandra Shields ${ }^{A}$ and Inayah Zaheen ${ }^{B}$
}

\section{Introduction}

Research in 2017 by the Royal College of Anaesthetists identified that junior doctors feel their work has a direct negative impact on their mental health. ${ }^{1}$ Research including by Balint et al, ${ }^{2}$ and more recently The King's Fund, ${ }^{3}$ has repeatedly shown that reflection circles and Balint groups improve healthcare professionals' mental health outcomes. The foundation programme provides supervisor support, but there is no formal peer-based support platform.

Our goal was to identify whether formal reflection circles named 'Reflect and rehydrate' (R\&R) sessions could improve and aid development of coping mechanisms for foundation doctors in a structured, confidential environment.

\section{Methods}

We created questionnaires to assess foundation year 1 (FY1) anxieties and approaches to coping, and disseminated them to current FY1 doctors and final-year medical students.

Structured R\&R sessions were chaired in a confidential, peersupported setting. Chairpersons presented reflection-based cases, encouraging participants to share experiences, allowing spontaneous reflection. Topics ranged from difficult patient encounters to unexpected death. After sessions, feedback was gathered via questionnaires. A proforma was created to encourage the model to be replicated elsewhere.

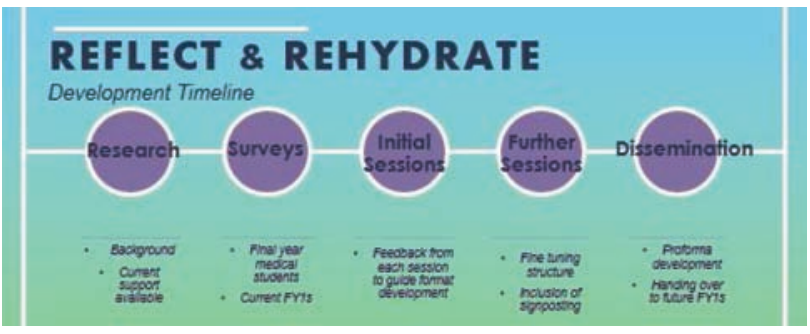

Fig 1. R\&R development timeline.

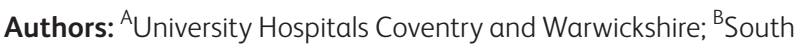
Warwickshire Foundation Trust, Warwickshire, UK
SOUTH WARWICKSHIDE NHS FOUNDATION TRUST

HOW TO SET UP

REFLECT \&

REHYDRATE

A peer supported reflection circle for toundation doctors

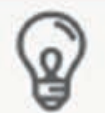

1. IOENTIFY A THEME \& FIND CASES

Ideatily a these that cas add structure to the asuion. Dumplex car

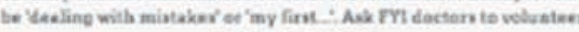
to shere thali story.

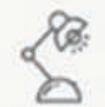

2. ARRANGE THE SESSION

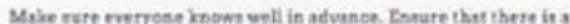
plas - allow each persea to upeak for 5 mientes and opea up to gaA ase open rebectiea/discussion

DON'T FOROET THE SECONO RI - REHYORATE. MAKE SURE TO PROVIDE DLENTY OF SNACKS/TEAICOFFE

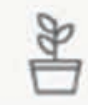

3. MAKE SURE TO SICNPOST

Remember. The purpose of Rsh in ack to replace the role of prolenianel - grewp rafiaction can certeialy improve ceping strate gies but make sure to slgescot mbete fir can get more help.

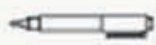

4. CATHER FECOBACK

Usdertanding what went well and whet could be improved is very impertant to swers that the gosin of the seutea are met Send eut o ferstbeck form and enabli feedback to shwje structure of fature mesciges

REFLCT S REHYORATE

Fig 2. How to set up an R\&R. 


\section{Results and discussion}

Final-year students reported that support from current foundation doctors would be the most helpful to prepare for coping with FY1. Current FY1 doctors reported that they felt the best wellbeing support came from their peers. Participant feedback from R\&R sessions was excellent, improving as the sessions developed.

Recurrent feedback themes included participants feeling at ease in the confidential, relaxed setting, comfortable to share experiences. Participants learned from the shared experiences of others and felt encouraged that others had had similar experiences, while the sessions directly improved their coping strategies. The impact has been huge: the sessions are now a regular fixture in the FY1 schedule at South Warwickshire NHS Foundation Trust, with interest from several other groups including newly qualified nurses, administration teams and allied health professionals.

\section{Conclusion}

We acknowledge that factors contributing to mental wellbeing are multifactorial and complex. However, there is evidence of improvement in coping abilities through R\&R sessions. We believe that further propagating this model nationwide can only be beneficial overall to wellbeing and, importantly, impacting on clinical practice and improving patient safety, as healthy junior doctors make for efficient and safe patient care.

\section{References}

1 Royal College of Anaesthetists. A report on the welfare, morale and experiences of anaesthetists in training: the need to listen. London: RCoA, December 2017. www.rcoa.ac.uk/document-store/welfaremorale-report-2017 [Accessed 18 March 2019].

2 Balint M. The doctor, his patient and the illness. London: Pitman Medical Publishing Co Ltd, 1964.

3 The King's Fund. Schwartz Center Rounds: Evaluation of the UK pilots. London: The King's Fund, 2011. www.kingsfund.org.uk/ sites/default/files/field/field_publication_file/schwartz-centerrounds-pilot-evaluation-jun11.pdf [Accessed 18 March 2019]. 